References

Derry, D. M., Anderman, F., Fawcett, J. S., and Wolfe, L. S. (1968). Late infantile systemic lipidosis: major monosialogangliosidosis: delineation of two types. Neurology (Minneapolis), 18, 340-348.

Landing, B. H., Silverman, F. N., Craig, J. M. (1964). Familial neurovisceral lipidosis. American Journal of Diseases of Children, 108, 503-522.

Nadler, H. L., and Gerbie, A. B. (1970). Role of amniocentesis in the intrauterine detection of genetic disorders. New England Journal of Medicine, 282, 596-599.

O'Brien, J. (1969). Generalized gangliosidosis. Journal of Pediatrics, 75, 167-186.

Okada, S., and O'Brien, J. D. (1968). Generalized gangliosidosis, B-galactosidase deficiency. Science, 160, 1002-1004.

Suzuki, K. (1968). Cerebral GM1 gangliosidosis: chemical pathology of visceral organs. Science, 159, 1471-1472.

Svennerholm, L. (1964). The gangliosides. Journal of Lipid Research, 5, 145-155.

Wolfe, L. S., Callahan, J., Fawcett, J. S., Andermann, F., and Scriver, C. R. (1970). GM1-gangliosidosis without chondrodystrophy or visceromegaly. Neurology (Minneapolis), 20, 23-44.

\section{Reproductive ability of an adult female with Silver-Russell syndrome ${ }^{1}$}

SUMMARY An adult female with typical features of Silver-Russell dwarfism gave birth to a viable infant. Despite the abnormalities in sexual development that may be associated with the SilverRussell syndrome, fertility is not necessarily impaired, at least in females.

The growth and development of children with the Silver-Russell syndrome have been studied (Silver, 1964; Tanner et al., 1975). There is, however, virtually no information available about adult patients with this syndrome. It is known that both male and female Silver-Russell dwarfs develop secondary sexual characteristics (Rimoin, 1969; McDowell and Sproles, 1973) but fertility of these patients has not been described previously.

\section{Case report}

The patient is a Puerto Rican female, born when her father and mother were 24 years of age. She was the second of 3 children; the 2 sisters were normal and over $152 \mathrm{~cm}$ tall. A paternal aunt and a paternal uncle are short in comparison to other family

1Supported by a grant from the National Institutes of Health (GM 19100). members. The patient's mother is $157 \mathrm{~cm}$ tall and her father is $175 \mathrm{~cm}$ tall. During the patient's gestation her mother gained only $\mathbf{4 5 3 5} \mathrm{g}$ though she was delivered at term. Birthweight was only $1871 \mathrm{~g}$. During infancy the patient had severe feeding difficulties and exhibited poor weight gain and excessive sweating. A grand mal seizure occurred at 1 month of age, at which time a doctor diagnosed hydrocephalus. At 3 months, asymmetry of the extremities (smaller on the right) and congenital dislocation of both hips were noted. The anterior fontanelle was large up to age 18 months.

Motor development was slow, with poor head control until 8 months of age, and walking began at 2 years. Language development was normal, however, and the patient's intelligence remains above average.

Evaluation at another hospital in New York City at age 9 years revealed a height of $99 \mathrm{~cm}$ (50th centile for $3 \frac{1}{2}$ years) and weight of $11.8 \mathrm{~kg}$ (50th centile for $2 \frac{1}{2}$ years). The diminished size of the right upper and lower extremities was noted. The development of sexual characteristics was described as early, but the exact age was not recalled. Menarche occurred at age 11 years in the patient, and at ages 13 years and 15 years in her younger and older sisters, respectively. Bone age was less than 6 years at 9 years chronological age, and was 8 years at 11 years, 8 months of age.

The patient married a paternal first cousin, and at 26 years of age gave birth to a son after a 7-month gestation. Delivery was uncomplicated, and the infant's birthweight was $1927 \mathrm{~g}$. The son had bilateral cleft lip and palate, normal intelligence, and stature slightly below the third centile, but did not have features of Silver-Russell syndrome.

At the time of this investigation, the patient was 32 years old, her height was $131 \mathrm{~cm}$ and weight $25 \mathrm{~kg}$. She had microcephaly with a head circumference of $48.5 \mathrm{~cm}$. The face is triangular with mild micrognathia and turned down corners of the mouth(Fig. 1). The palate was slightly high arched, and the teeth were crowded. The left pinna was simple and larger than the right. The hairline was normal for a female. The neck was not webbed, and the chest configuration was normal and symmetrical. Breast development was normal. The abdomen appeared protuberant because of a lordotic posture. There was female distribution of pubic hair. The trunk and extremities were asymmetrical (Fig. 2). The right and left upper extremities measured $50.5 \mathrm{~cm}$ and 53.25 $\mathrm{cm}$, respectively from the acromion to the tip of the 5th finger; there was a $2 \mathrm{~cm}$ leg length discrepancy, the left larger than the right, and the maximal calf circumference was $24.25 \mathrm{~cm}$ on the left and $21.75 \mathrm{~cm}$ on the right. There was a limitation of hip abduction to $30^{\circ}$ bilaterally. The feet showed partial syndactyly 


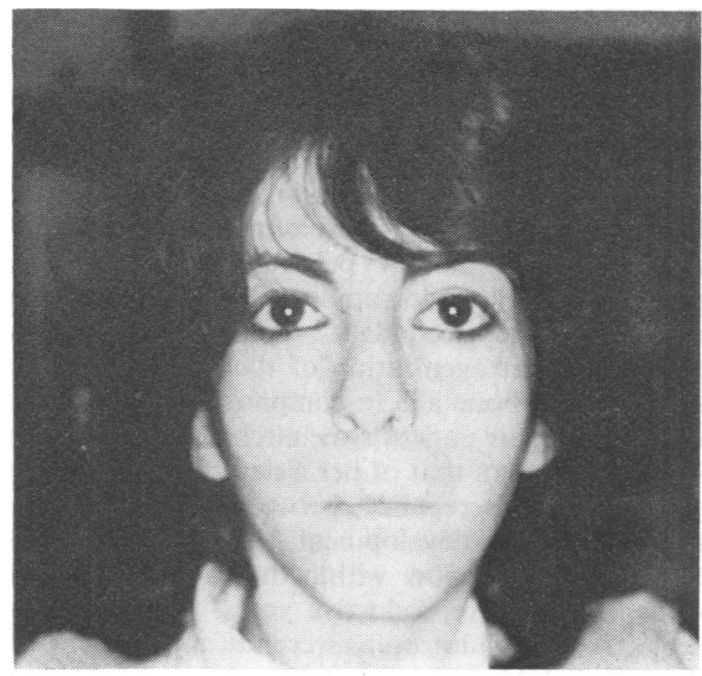

Fig. 1 Facial features, showing triangular facies.

of the second and third toes, and an increased longitudinal arch. There was bilateral brachyclinodactyly (Fig. 3) and a 1.5 by $2 \mathrm{~cm}$ café au lait spot over the sacrum.

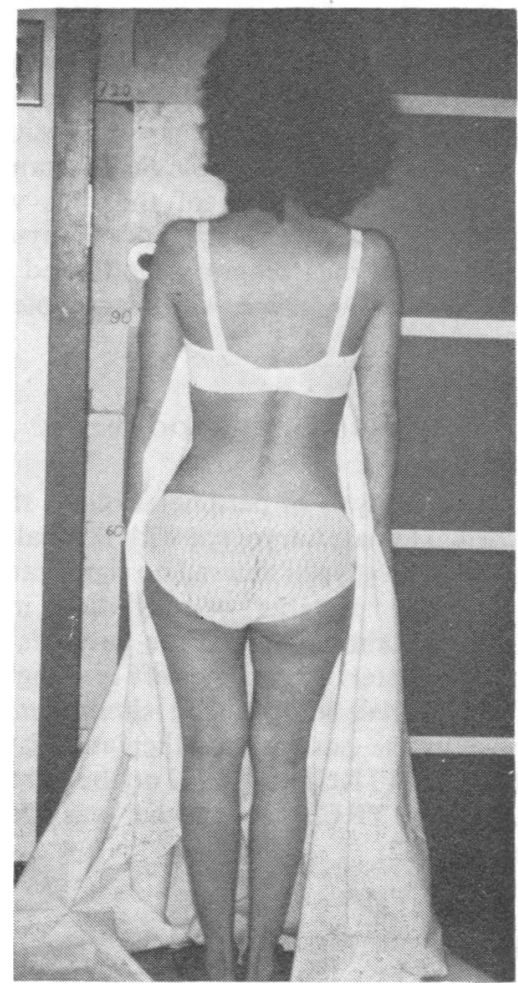

Fig. 2 Posterior view of the trunk and extremities, showing body asymmetry.

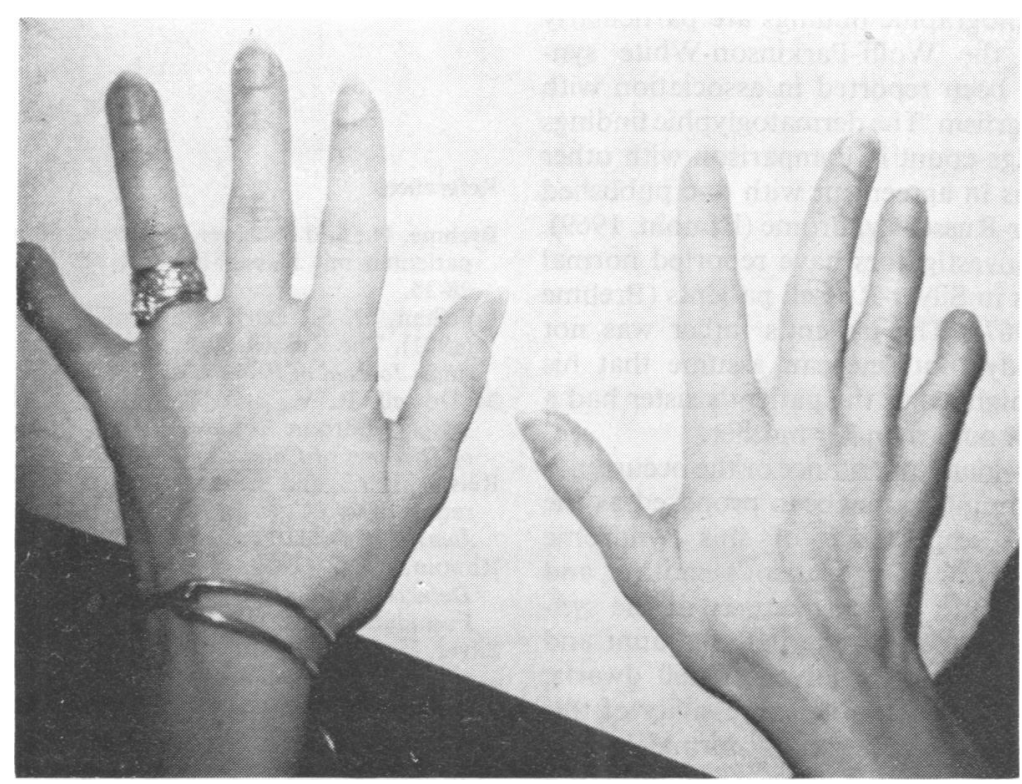

Fig. 3 Dorsal view of hands, showing bilateral brachyclinodactyly of fifth fingers. 


\section{LABORATORY INVESTIGATIONS}

A complete blood count and routine urinalysis and all serum chemistry determinations were normal. A 24-hour urine for gonadotropins was positive at 8 mouse uterine units. Radiological examination showed bilateral dislocation of the hips with deformity of the femoral heads; all epiphyses were closed. An electrocardiogram indicated WolffParkinson-White syndrome, with incomplete right bundle-branch block.

\section{CYTOGENETIC AND DERMATOGLYPHIC STUDIES}

Chromosome analysis of peripheral blood showed a 46,XX normal female karyotype with normal Giemsa banding. Dermatoglyphs showed no significant asymmetry of finger patterns or deviation in finger pattern type in comparison to the patient's mother and her older sister. Right and left atd angles were 42 and 44 degrees, respectively; similar atd angles were noted in the patient's mother and sister. The total ridge count (TRC) was 98 ( 52 on the right, and 46 on the left). The TRC of the mother was 126 and of the sister was 152 .

\section{Discussion}

This patient's history and physical features fulfil the criteria of the Silver-Russell syndrome (Reister and Scherz, 1964; Silver, 1964).

The electrocardiographic findings are particularly interesting since the Wolff-Parkinson-White syndrome has never been reported in association with Silver-Russell dwarfism. The dermatoglyphic findings of a low total ridge count in comparison with other family members is in agreement with one published study of the Silver-Russell syndrome (Rimoin, 1969). However, other investigators have reported normal total ridge counts in Silver-Russell patients (Brehme and Schroter, 1967). The patient's father was not available for study, but one can assume that his ridge count was high, since the patient's sister had a higher total ridge count than her mother.

Autosomal dominant inheritance or the occurrence of a single gene mutation has been proposed as the genetic basis for appearance of this syndrome (Fuleihan et al., 1971). Our patient's mother and younger sister have no clinical features of the syndrome. It is conceivable that the paternal aunt and uncle with short stature are Silver-Russell dwarfs, and that because of the variable expressivity of this condition, the patient's father is of normal height. However, the possibilities of a de novo mutation or a non-genetic aetiology cannot be ruled out.
The novel feature presented by our patient is her ability to conceive and undergo vaginal delivery of an infant who weighed over $1814 \mathrm{~g}$. One might expect that a woman with Silver-Russell dwarfism would have difficulty becoming pregnant and giving birth, since patients with this condition show abnormalities in the pattern of sexual development (Silver, 1964), and also have narrow pelvises. Silver described raised urinary gonadotropins, early development of menarche, and secondary sexual characteristics, premature oestrogenization of the vaginal mucosa, and retarded bone age in comparison to sexual development. This patient's menarche occurred somewhat earlier than that of her sisters, and her history indicated a discrepancy between bone age and secondary sexual development. Her urinary gonadotropin levels are now within the range of normal women in their reproductive years. Unfortunately, her urinary gonadotropins were not measured when she was a child.

The authors are grateful to Mrs Hanna Dar for her assistance with dermatoglyphic interpretation.

Helen K. Abramowicz and Harold M. Nitowsky

From the Department of Pediatrics and the Rose F. Kennedy Center for Research in Mental Retardation and Human Development of the Albert Einstein College of Medicine of Yeshiva University, Bronx, New York 10461

\section{References}

Brehme, H., and Schroter, R. (1969). Hautleisbefunde von 15 patienten mit Russell-Silver-Syndrome. Humangenetik, 5, 28-35.

Fuleihan, D. S., DerKaloustian, V. M., and Najjar, S. S. (1971). The Russell-Silver syndrome. Report on three siblings. Journal of Pediatrics, 78, 654-657.

McDowell, R. V., and Sproles, E. T. (1973). The RussellSilver syndrome, a nine-year follow-up. American Journal of Diseases of Children, 126, 794-796.

Reister, H. C., and Scherz, R. G. (1964). Silver syndrome-A report of two cases and a review of the literature. American Journal of Diseases of Children, 107, 410-416.

Rimoin, D. L. (1969). The Silver syndrome in twins. Birth Defects: Original Article Series, 5, No. 2, 183-187. National Foundation-March of Dimes, New York.

Silver, H. K. (1964). Asymmetry, short stature, and variations of sexual development. American Journal of Diseases of Children, 107, 495-515.

Tanner, J. M., Lejarraga, H., and Cameron, N. (1975). The natural history of the Silver-Russell syndrome: a longitudinal study of thirty-nine cases. Pediatric Research, 9, 611623. 